\title{
Technique for transvaginal removal of large specimen using an Alexis Contained Extraction System during laparoscopic hysterectomy
}

Iori Kisu, MD, PhD ${ }^{1,2}$, Kouji Banno, MD, PhD², Asahi Tokuoka, MD¹, Keigo Yamaguchi, MD¹, Kunio Tanaka, MD', Tetsuro Shiraishi, MD¹, Kanako Nakamura, MD, PhD¹, Hiroshi Senba, MD, PhD¹, Kiyoko Matsuda, MD, PhD', Nobumaru Hirao, MD, PhD ${ }^{1}$

\footnotetext{
${ }^{1}$ Department of Obstetrics and Gynecology, Federation of National Public Service Personnel Mutual Aid Associations, Tachikawa Hospital, ${ }^{2}$ Keio University School of Medicine, Tokyo, Japan
}

\section{Objective}

Transvaginal removal of large specimens during laparoscopic hysterectomy can be a complex surgical procedure that poses a risk of organ injury and tissue spillage into the abdominal cavity and is associated with extraction of the specimen and manual morcellation. Our objective was to demonstrate a technique for transvaginal removal of large specimens using the Alexis Contained Extraction System (CES) in laparoscopic hysterectomy.

\section{Methods}

The technique used for transvaginal removal of large specimens using the Alexis CES was presented in this video. Surgery was performed at a tertiary hospital.

\section{Results}

Following resection of the specimen during laparoscopic hysterectomy, the Alexis CES was inserted into the abdominal cavity through the umbilical trocar wound. The specimen was placed in a bag to prevent tissue spillage. The ring retractor was guided to the vagina and pulled out transvaginally. By repeatedly turning the ring retractor, tension was applied to the specimen bag, and the vaginal wall was unfolded all around to enable a secure surgical field. During manual morcellation of the specimen in the bag, the retractor was pulled and additionally turned to roll and re-tension the specimen bag when the bag was loosened. The specimen was pushed out of the vagina and safely and effectively extracted without concerns about tissue spillage in the abdominal cavity or related organ injuries.

\section{Conclusion}

The technique for transvaginal removal of large specimens using the Alexis CES enables simple, effective, and safe tissue extraction with contained manual morcellation during laparoscopic hysterectomy.

Keywords: Morcellation; Laparoscopy; Hysterectomy

With advances in surgical techniques and devices, the use of minimally invasive surgery at present encompasses extraction of even large specimens; however, extraction of specimens from giant myoma and adenomyosis poses a major challenge $[1,2]$. In minimally invasive gynecologic surgery, extraction of large specimens is commonly performed with or without manual or electromechanical morcellation, either through the trocar wound with an extended incision, an additional abdominal wound, or the vaginal canal [3]. Inefficient tissue containment and extraction can potentially affect patient
Received: 2021.12.05. Accepted: 2022.01.05.

Corresponding author: Iori Kisu, $\mathrm{MD}, \mathrm{PhD}$

Department of Obstetrics and Gynecology, Federation of National Public Service Personnel Mutual Aid Associations, Tachikawa Hospital, 4-2-22 Nishiki-cho, Tachikaw, Tokyo 1908531, Japan E-mail: iori71march@hotmail.co.jp

https://orcid.org/0000-0003-1143-9855

Articles published in Obstet Gynecol Sci are open-access, distributed under the terms of the Creative Commons Attribution Non-Commercial License (http://creativecommons org/licenses/by-nc/3.0/) which permits unrestricted non-commercial use, distribution, and reproduction in any medium, provided the original work is properly cited.

Copyright $\odot 2022$ Korean Society of Obstetrics and Gynecology 


\title{
Obstetrics \& Gynecology Science
}

\author{
Vol. 65, No. 3, 2022
}

safety and postoperative outcomes [4]. Therefore, tissue containment and extraction are becoming increasingly important elements in surgical procedures [5]. In laparoscopic or robotic hysterectomy for benign gynecological diseases, the resected vaginal canal is often used as a pathway to remove the specimen transvaginally, often necessitating tissue morcellation for extraction of large specimens. However, in patients with obesity, nullipara, and narrow or atrophic vagina, transvaginal removal of large specimens in cases of benign disease can be a complex surgical procedure that poses a risk of organ injuries involving the vaginal and perineal wall, bladder, and intestinal tracts due to lack of an adequate surgical field. Furthermore, consideration must be given to tissue spillage into the abdominal cavity associated with extraction of the specimen and manual morcellation [4-6]. Thus, safe and efficient extraction procedures and surgical devices are required to avoid these complications and concerns in such situations.

The Alexis Contained Extraction System (CES) (Applied Medical, Rancho Santa Margarita, (A, USA) is a device that consists of a rigid ring retractor of $14 \mathrm{~cm}$ or $17 \mathrm{~cm}$ in diameter and a contained bag with a capacity of $3,400 \mathrm{~mL}$ or $6,500 \mathrm{~mL}$, which is mainly used for extraction of specimens in minimally invasive gastrointestinal surgery. The Alexis CES facilitates easy and safe extraction of specimens from the abdominal cavity through the abdominal wall by providing atraumatic abdominal wall retraction. Further, it stores the specimens in a bag to prevent tissue spillage and contamination of the abdominal cavity by gastrointestinal bacteria associated with extraction of the specimen $[7,8]$. Although transabdominal use of the Alexis CES in minimally invasive gastrointestinal surgery has been discussed in previous reports $[7,8]$, to the best of our knowledge, its use in transvaginal extraction of specimens related to the field of minimally invasive gynecologic surgery has not been reported.

Herein, we demonstrate a technique that enables safe and effective transvaginal removal of large specimens using the Alexis CES in laparoscopic hysterectomy. After resection of the specimen during laparoscopic hysterectomy, the Alexis CES was inserted into the abdominal cavity through the umbilical trocar wound. The specimen was placed in a bag to prevent tissue spillage. The ring retractor was then guided to the vagina and pulled out through the vaginal canal. By repeatedly turning the ring retractor, tension was applied to the specimen bag, and the vaginal wall was unfolded all around, thereby providing a secured surgical field (Fig.1).

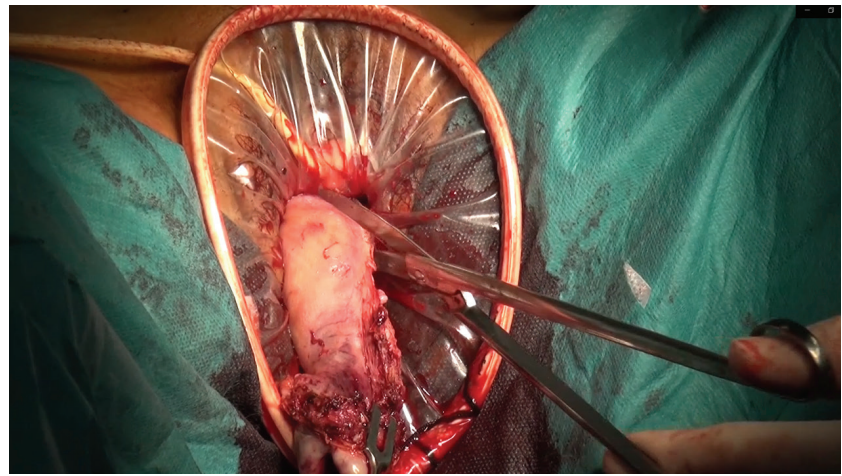

Fig. 1. Transvaginal removal of the specimen using the Alexis Contained Extraction System (CES) during laparoscopic hysterectomy. The Alexis CES enables effective and safe tissue specimen extraction by maintaining a secure surgical field and applying tension to the specimen bag.

During manual morcellation of the specimen outside the bag, the retractor was pulled and turned to roll and re-tense the specimen bag when the tension of the bag was loosened as the process of morcellation advanced. By applying continuous tension to the bag, the specimen is pushed out of the vagina and safely and effectively extracted without concerns about tissue spillage in the abdominal cavity and the related complications of organ injuries involving the vaginal wall, bladder, and intestinal tracts.

In conclusion, tissue containment and extraction of large specimens is a major challenging procedure in minimally invasive surgery, but this technique for transvaginal removal of large specimens using the Alexis CES enables simple, effective, and safe tissue extraction with contained manual morcellation in laparoscopic hysterectomy.

\section{Conflict of interest}

We declare no potential conflict of interest relevant to this article.

\section{Ethical approval}

This study was approved by the Institutional Review Board (IRB) of the Federation of National Public Service Personnel Mutual Aid Associations, Tachikawa Hospital (IRB No. 202104). The study was performed in accordance with the prin- 


\section{Obstetrics \& Gynecology Science}

Iori Kisu, et al. Transvaginal removal with an Alexis CES

ciples of the Declaration of Helsinki.

\section{Patient consent}

The patient provided written informed consent for publication of this manuscript and related videos.

\section{Funding information}

None.

\section{Video clip}

Video can be found with this article online at https://doi. org/10.5468/ogs.21358.

\section{References}

1. Moawad GN, Tyan P, Awad C. Technique for tissue containment and extraction in the complex minimally invasive myomectomy setting. J Minim Invasive Gynecol 2019;26:809-10.

2. Vargas MV, Moawad GN, Sievers C, Opoku-Anane J, Marfori CQ, Tyan P, et al. Feasibility, safety, and predic- tion of complications for minimally invasive myomectomy in women with large and numerous myomata. J Minim Invasive Gynecol 2017;24:315-22.

3. Hong DH, Kim M, Kim K, Suh DH, No JH, Kim YB. Use of a ring retractor to facilitate specimen removal in laparoscopic surgery. Obstet Gynecol Sci 2020;63:548-9.

4. Stentz NC, Cooney LG, Sammel M, Shah DK. Changes in myomectomy practice after the U.S. food and drug administration safety communication on power morcellation. Obstet Gynecol 2017;129:1007-13.

5. Zapardiel I, Boria F, Halaska MJ, De Santiago J. Laparoscopic power morcellation: techniques to avoid tumoral spread. J Minim Invasive Gynecol 2021;28:1442-3.

6. Siedhoff MT, Doll KM, Clarke-Pearson DL, Rutstein SE. Laparoscopic hysterectomy with morcellation vs abdominal hysterectomy for presumed fibroids: an updated decision analysis following the 2014 Food and Drug Administration safety communications. Am J Obstet Gynecol 2017;216:259.e1-6.

7. Arenal JJ, Martínez A, Maderuelo MV, Tinoco C, Benito $C$, Citores MA, et al. Reduced wound infection in colorectal resection by using a wound auto-retractor. Infez Med 2016;24:310-7.

8. Cheng KP, Roslani AC, Sehha N, Kueh JH, Law CW, Chong HY, et al. ALEXIS O-Ring wound retractor vs conventional wound protection for the prevention of surgical site infections in colorectal resections(1). Colorectal Dis 2012;14:e346-51. 